\title{
ITIL AS A FRAMEWORK FOR MANAGEMENT OF CLOUD SERVICES
}

\author{
Soňa Karkošková ${ }^{1}$, George Feuerlicht ${ }^{2}$ \\ ${ }^{1}$ Faculty of Information Technology, University of Economics, Prague, W. Churchill Sqr. 4, 13067 Prague 3, Czech \\ Republic \\ ${ }^{2}$ Unicorn College, V Kapslovně 2767/2,130 00 Prague 3, Czech Republic
}

\begin{abstract}
Cloud computing is changing the way that organizations utilize IT resources with a corresponding impact on the role of enterprise architecture. Increasingly, IT infrastructure and application services are delivered as services over the internet making IT service management a key architectural concern. In this paper we describe our initial proposal for adapting the ITIL framework for the management of the lifecycle of cloud-based services. Taking the cloud consumer perspective, we have redefined ITIL processes for the various lifecycle phases to reflect the needs of cloud service consumers.
\end{abstract}

Keywords: Enterprise Architecture, Cloud computing, ITIL

\section{INTRODUCTION}

Fast development of new technological solutions and increasing complexity of business processes challenge the traditional methods of delivering IT (Information Technology) services. Organizations are looking for ways to ensure effective support for their business objectives without making excessive investments in IT and at the same time minimizing the effort spent on non-core activities. Cloud computing provides an opportunity for flexible acquisition of IT resources in the form of services provided over the Internet avoiding the limitations of on-premise IT solutions. Enterprise Architecture (EA) is a comprehensive set of principles that provides a blueprint for the design and implementation of different architectural layers and a systematic framework for the alignment of business and IT. It is recognized that EA can play an important role in decisions about cloud adoption and can help to identify and prioritize suitable cloud computing services [1]. An important function of modern EA is IT service management that establishes a uniform process framework for a servicebased environment and helps to reduce operating costs and increase efficiency of both internal and external services. While cloud computing does not change the basic principles of IT service management it requires a shift in the perspective, differentiating between the requirements of service consumers and service providers. Cloud computing addresses key IT challenges that include low resource utilization and high cost of IT, but in general the existing standards and best practices that organizations use to manage services are not well adapted for the transition to the cloud. It can be argued that immature EA makes it difficult for organizations to reach the expected benefits of cloud computing.

ITIL (Information Technology Infrastructure Library) is a widely used methodology framework for the implementation of IT Service Management that enables planning, design, selection, operation and continuous improvement of IT services. Applying the principles of ITIL provides organisations with methodology for managing IT services, but ITIL is primarily focused on on-premise solutions where resources are shared within a single organization and does not fully address the requirements of cloud computing [2].

We propose that both cloud and on-premise IT services can be mapped to service life-cycle stages and that ITIL can be adapted to incorporate cloud services. The result of ITIL adaptation for cloud environments involves a revision the processes defined in ITIL and application ITIL principles to implementation and management of cloud services. This paper presents initial results of a doctoral research project at the University of Economics, Prague and focuses on adapting the ITIL framework for the management of the lifecycle of cloud-based services. This research is a part of a larger project that includes work on categorization and classification of cloud services and design of a cloud service catalog based on a unified taxonomy of cloud services.

In the next section (section 2) we review related literature, and then in section 3 we discuss the adaptation of ITIL lifecycle phases to support the management of cloud services. The final section (section 4) gives our conclusions and directions for further work.

\section{RELATED WORK}

Cloud computing is a model that facilitates the provision of shared, scalable and flexible IT resources across the Internet. These resources are typically shared among a large number of users and are available on-demand, in a highly scalable and configurable manner. Cloud computing services are provided in real time and billed according to consumption based on the "pay-per-use" model. The benefits of cloud computing include lower costs, improved scalability and flexibility, but these advantages must be balanced against potential risks associated with security and availability of services. Cloud computing services can be categorized into three basic models [15]:

- Infrastructure-as-a-Service (IaaS) - provides a scalable IT infrastructure on which cloud 
consumers can deploy and run software, operating systems and applications

- $\quad$ Platform-as-a-Service (PaaS) - provides a scalable application development and deployment platform

- Software-as-a-Service (SaaS) - provides scalable software services (applications)

The specific characteristics of a particular cloud service depend on the type of service and may relate to requirements of availability, performance, flexibility, reliability, scalability, interoperability, portability, architectural compatibility and degree of integration [16].

Investigation of synergies between cloud computing and SOA (Service Oriented Architecture), and the role of EA in assisting organizations in the transition to cloud computing has been an active research area recently [3], [4], [5], [19]. Authors of [6] and [7] argue that mature EA and understanding of organizational and architectural requirements simplifies the transition to the cloud. Existing EA frameworks constitute a good starting point for successful adoption of cloud services [8], [9], but in general these frameworks do not fully address the requirements of service management for the cloud environment [2]. It can be argued that organizations that have a mature EA framework are better prepared for the adoption of new technologies in general, and that EA can assist in prioritizing adoption of individual cloud services minimizing the risk and maximizing the benefits of cloud adoption [6]. However, existing EA frameworks such as TOGAF or Zachman need to be adapted to provide effective support for cloud computing [8], [9]. More specifically, cloud computing shifts the focus from the management of on-premise hardware and software assets to service life-cycle management for both on-premise and cloud services [2]. ITIL [10] is a widely used methodological framework that provides a basis for the effective delivery of IT services [11], [12] and improves support for business objectives [13]. ITIL is focused on the development and support of IT service management through the use of well-defined processes, and can lead to improvement of the alignment of business and IT, and to a more flexible and responsive EA. However the current version of ITIL 2011 Edition lacks processes for managing specific features of cloud services [14]. Adaptation of the ITIL framework for cloud involves taking into account the specific responsibilities of cloud consumers and cloud providers.

\section{ADAPTING ITIL LIFECYCLE PHASES TO CLOUD COMPUTING}

ITIL is a standardized methodology for the implementation of IT Service Management (ITSM) that enables planning, selection, negotiation, acquisition, contracting, execution, operation and continuous improvement of IT services. The aim of ITSM is to achieve continuous service improvement (i.e. improvements in agility, cost reduction, etc.) and this may involve replacing existing services with services delivered by external (cloud) providers. ITSM can be used to understand how IT services deliver value for the end-user organization, identifying all costs associated with service delivery, and managing the transition to the cloud mitigating the risk of cloud adoption.

ITSM processes represent corresponding phases in the ITIL Service Lifecycle. Their scope is subject to interpretation according to specific business requirements. ITIL processes can differ based on the profile of the organization and this can affect their prioritization. Importantly, in the context of cloud services, ITIL processes can be interpreted from two different perspectives: 1) from the perspective of service provider, and 2) from the perspective of service consumer. In traditional, on-premise environments, both service provider and service consumer are typically part of the same organization and ITIL processes do not differentiate between these roles.

As the first step, the most relevant processes need to be analyzed and customized for the cloud environment taking the service consumer perspective. This involves the following considerations for the individual ITIL phases:

- $\quad$ Service Strategy phase: the strategic importance of cloud services, their value to the business, related risks, costs and benefits are identified.

- $\quad$ Service Design phase: ITIL processes are relevant during negotiations with service providers ensuring that the IT infrastructure is secure and highly available and has sufficient capacity to handle the service consumer requirements.

- $\quad$ Service Transition phase: ITIL processes help to ensure a successful transition to the cloud environment, providing guidelines for the deployment cloud services.

- Service Operation phase: ITIL processes define division of responsibilities between the service consumer and service provider for the management of incidents, coordinating responses to events and ensuring that agreed service levels are maintained.

- Continual Service Improvement phase: involves service monitoring for compliance with SLAs (Service Level Agreements) and continuous improvement of service features and functionality. This may involve replacing services by more suitable cloud services as these become available.

Taking the cloud service consumer perspective, we have identified relevant ITIL processes and listed these processes according to ITIL Service Lifecycle phase. The following sections describe the ITIL Service Lifecycle phases: Service Strategy, Service Design, Service Transition, Service Operation and Continual Service Improvement in the context of cloud services.

\subsection{Service Strategy}

Cloud computing does not change the strategic objectives of the organization, but it provides new opportunities for achieving these objectives. Transition to the cloud is an enterprise-level endeavour requiring a holistic approach to strategic, tactical and implementation planning that includes the assessment of the readiness of the organization for cloud 
adoption. Good strategy can be transformational adding value to the organization and enhancing its business agility [17]. It must take into account existing assets and complement these assets with the new assets that can be quickly implemented to increase business agility. Any strategic activity must be fully supported at the top management level and take into consideration competitive pressures that can influence cloud adoption decisions [1]. Strategic planning makes use of the existing EA for the assessment of business impact and value, criticality, usability and technical and architectural suitability, security and risk assessment, organizational readiness and legal and compliance issues. The outcome of this evaluation determines priority areas for migrating to the cloud that are expected to deliver high value, minimize risk, and in general, maximize the benefits of cloud adoption.

The strategy phase involves a review of the service portfolio. Portfolio of services includes both internal and external services and provides a description of the features of information of services. Strategy phase should ensure that all services are aligned to the defined strategy and business objectives, and provide value to the organization. Service portfolio management is closely related to financial management and it is the main source for obtaining financial information to compare service cost of different providers. The nature of provisioning of cloud services requires changes in the way IT services are charged for, and how the costs of services are distributed, and involves the identification of costs and benefits associated with migrating IT systems to the cloud. Cost-benefit analysis enables the comparison of the value of cloud computing services to the value of on-premise IT [18]. The cost-benefit analysis should include considerations of the appropriate ratio of onpremise and cloud computing services. A more differentiated framework for the comparison of cloud computing solutions with the traditional on-premise model involves estimates of the Total Cost of Ownership (TCO). Result of this comparison is an absolute cost advantage over the entire useful life of the IT solution. To fully compare the economic impact of cloud computing solutions with onpremise alternatives, qualitative aspects need to be also considered, as quantifiable factors represent only part of considerations. This includes the evaluation of indirect monetary measurable and intangible benefit contributions of cloud computing, and considerations of profitability and efficiency. Profitability and efficiency improvements with potential reduction in TCO arise from the transition from the on-premise model characterized by Capital Expenditure (CapEx) in software, hardware and infrastructure to the "pay-per-use" cloud model that involves primarily Operational Expenses (OpEx). Other widely accepted methods include Net Present Value calculation and the payback method [20].

Demand Management requires interaction between service consumer and provider. Provider needs to make the required capacity for demand-oriented services available to meet the needs of consumers. Consumers need to have good understanding of the functional and non-functional characteristics of the services, including seasonal demand variations and associated pricing models, to allow comparison of the services offered by different cloud providers and identification of the services that meet their requirements. Special consideration should be given to mission-critical services as such services have a high demand on availability, and their outages can have direct impact on business continuity. Implementation of demand management ensures the identification of suitable services, and may also identify opportunities for cost savings. ITIL Service Strategy processes adapted to cloud computing are listed in Table 1 below.

Table 1 ITIL Service Strategy processes adapted to cloud computing

\begin{tabular}{|l|l|}
\hline ITIL Process & Cloud consumer perspective \\
\hline Generation & $\begin{array}{l}\text { Define cloud adoption strategy } \\
\text { Identify areas and processes suitable } \\
\text { for transition to the cloud }\end{array}$ \\
\hline $\begin{array}{l}\text { Service Portfolio } \\
\text { Management }\end{array}$ & $\begin{array}{l}\text { Identify available cloud services } \\
\text { describing their cost model, and } \\
\text { service attributes and capabilities }\end{array}$ \\
\hline $\begin{array}{l}\text { Financial } \\
\text { Management }\end{array}$ & $\begin{array}{l}\text { Provide information about cloud } \\
\text { pricing models and conduct costs and } \\
\text { benefits analysis } \\
\text { Quantification of the value of services } \\
\text { Budgeting }\end{array}$ \\
\hline $\begin{array}{l}\text { Demand } \\
\text { Management }\end{array}$ & $\begin{array}{l}\text { Identify the optimum level of IT } \\
\text { resources, } \\
\text { Identify elasticity requirements to } \\
\text { support key business processes }\end{array}$ \\
\hline $\begin{array}{l}\text { Organizational a proposal for cloud service } \\
\text { Development }\end{array}$ & $\begin{array}{l}\text { implementation strategy } \\
\text { Define responsibilities } \\
\text { respont roles and }\end{array}$ \\
\hline
\end{tabular}

\subsection{Service Design}

Service Design phase includes service management processes and tools needed to manage key processes to ensure continual improvement of performance, security, business continuity, and the management of business relationships. Information about services that are already in the productions and planned services must be stored in the Service Catalog in order to document services and identify opportunities for service optimization. Service catalog contains detailed documentation about services and associated business processes, service integration requirements, and tools needed to support service operation. Information about alternative services and providers should be also maintained in the service catalog.

Another important aspect of service design involves Service Level Management. Service Level Management can facilitate improvements of existing services as well as the implementation of new or changed business requirements. Establishing Service Level Agreements (SLAs) with cloud provider helps to communicate the expectation and avoid misalignment between business needs and a corresponding technical solution. SLA should give a clear understanding of 
the expected level of service and the associated costs, and define the responsibilities of both the provider and the consumer. SLA should identify specific and measurable indicators (metrics) that can be used for evaluation of the service. Service Level Management defines the interface between cloud service provider and consumer in the form of a contractual agreement. Service provider should assume responsibility for the availability, confidentiality, integrity and reliability of services as defined by the SLA, and has the obligation to proactively identify security risks and availability problems. The consumer should monitor performance of services to ensure conformance with the corresponding SLAs and take action in the case of any departure from the SLA. Consumers should have the right to conduct audits to determine whether the agreed security levels have been achieved. The rules regulating user access to data must be clearly defined. The process of Supplier Management aims to ensure that provider complies with the relevant SLAs. ITIL Service Design processes adapted to cloud computing are listed in Table 2 below.

Table 2: ITIL Service Design processes adapted to cloud computing

\begin{tabular}{|l|l|}
\hline \multicolumn{1}{|c|}{ ITIL Process } & \multicolumn{1}{|c|}{ Cloud consumer perspective } \\
\hline $\begin{array}{l}\text { Service } \\
\text { Catalogue } \\
\text { Management }\end{array}$ & $\begin{array}{l}\text { Define functional and non-functional } \\
\text { characteristics of internal and external } \\
\text { (cloud) services and their relationshipsto } \\
\text { underlying IT capabilities }\end{array}$ \\
\hline $\begin{array}{l}\text { Service Level } \\
\text { Management }\end{array}$ & $\begin{array}{l}\text { Specify agreed SLAs and related metrics } \\
\text { Implement contractual arrangements }\end{array}$ \\
\hline $\begin{array}{l}\text { Availability } \\
\text { Management }\end{array}$ & $\begin{array}{l}\text { Conduct risk assessment and develop } \\
\text { procedures to ensure availability of } \\
\text { services }\end{array}$ \\
\hline $\begin{array}{l}\text { IT } \\
\text { Continuity } \\
\text { Management }\end{array}$ & $\begin{array}{l}\text { Ensure business continuity by defining } \\
\text { disaster recovery procedures } \\
\text { Identify alternative cloud providers }\end{array}$ \\
\hline $\begin{array}{l}\text { Information } \\
\text { Security } \\
\text { Management }\end{array}$ & $\begin{array}{l}\text { Develop security policies and procedures } \\
\text { to ensure confidentiality, availability and } \\
\text { integrity of cloud data }\end{array}$ \\
\hline $\begin{array}{l}\text { Supplier } \\
\text { Management }\end{array}$ & $\begin{array}{l}\text { Evaluate cloud service providers and } \\
\text { manage the relationship with service } \\
\text { providers }\end{array}$ \\
\hline
\end{tabular}

\subsection{Service Transition}

Process of Transition Planning and Support provides planning and scheduling the necessary capacity and resources in order to deploy services into operation. It includes testing and evaluation to ensure the integrity of all identified user assets and assessment of readiness of the internal and external services. Cloud computing environments are highly dynamic, often requiring rapid provisioning of scalable services. However, standard methods and procedures for change management must be documented and followed to minimize business risks, and all changes in the type and volume of services must be recorded and documented. Each change request must be approved and its impact on related assets must be evaluated. Service consumers and providers should agree on the allocation of responsibilities to manage service changes. The
Evaluation process provides the information needed to assess whether a new service or service change can be validated and approved for deployment.

Process Knowledge Management is essential for maintaining a successful relationship between the service consumer and service provider and for sharing information and data between them. Data ownership should be clarified and all data generated by the service consumer should remain the property of the consumer, allowing the consumer to change providers when the need arises, maintaining the confidentiality and integrity of data. ITIL Service Design processes adapted to cloud computing are listed in Table 3 below.

Table 3. ITIL Service Transition processes adapted to cloud computing

\begin{tabular}{|l|l|}
\hline \multicolumn{1}{|c|}{ ITIL Process } & \multicolumn{1}{|c|}{ Cloud consumer perspective } \\
\hline $\begin{array}{l}\text { Transition } \\
\text { Planning and } \\
\text { Support }\end{array}$ & $\begin{array}{l}\text { Plan and coordinate the transition } \\
\text { to cloud environment }\end{array}$ \\
\hline $\begin{array}{l}\text { Change } \\
\text { Management }\end{array}$ & $\begin{array}{l}\text { Ensure that all service changes are } \\
\text { evaluated, approved, implemented } \\
\text { and reviewed in a controlled } \\
\text { manner }\end{array}$ \\
\hline Evaluation & $\begin{array}{l}\text { Develop evaluation procedures to } \\
\text { ensure that services are consistent } \\
\text { with business requirements }\end{array}$ \\
\hline $\begin{array}{l}\text { Knowledge } \\
\text { Management }\end{array}$ & $\begin{array}{l}\text { Provide reliable and accurate } \\
\text { information needed for decision } \\
\text { making to the responsible persons }\end{array}$ \\
\hline
\end{tabular}

\subsection{Service Operation}

Cloud computing services as any other IT services must be continuously monitored to ensure compliance with the corresponding SLAs. The metrics obtained in this phase may trigger service re-design or replacement requests and activate relevant Service Design and Service Transition processes. An important part of the Service Operation phase is the creation and management of the Service Desk. Service Desk supports rapid problem identification and resolution ensuring continuity of operations. The Event Management process monitors all events that occur during the operation of services. The purpose of this process is to detect deviations from the expected service functionality and to escalate events in a pre-defined way. The service provider must ensure an appropriate level of monitoring for all services and maintain agreed level of availability as specified in the SLA. Consumer should monitor delivered services and report occurrences of events that indicate deviations from the desired service functionality. Both provider and consumer must have a common view of all events and understanding of the level of criticality of the events and escalation strategy that leads to rapid problem resolution.

To ensure secure operation only users with the relevant access privileges should be able to activate services that implement business processes that they are responsible for. 
Access Management of cloud services should remain the responsibility of service consumers and is typically implement using provider Access Management system. Service consumer should regularly audit access permissions to ensure their correctness. ITIL Service Operation processes adapted to cloud computing are listed in Table 4 below.

Table 4: ITIL Service Operation processes adapted to cloud computing

\begin{tabular}{|l|l|}
\hline \multicolumn{1}{|c|}{ ITIL Process } & \multicolumn{1}{|c|}{ Cloud consumer perspective } \\
\hline Event & $\begin{array}{l}\text { Monitor service events and trigger the } \\
\text { required actions escalating to cloud } \\
\text { service provider, if required }\end{array}$ \\
\hline $\begin{array}{l}\text { Access } \\
\text { Management }\end{array}$ & $\begin{array}{l}\text { Ensure that only authorized users are } \\
\text { allowed access to services }\end{array}$ \\
\hline
\end{tabular}

\subsection{Continual Service Improvement}

Comprehensive documentation of business requirements and IT capabilities of the organization is essential for the identification of opportunities for improvement of services. Collecting service metrics and other information about the operation of services helps to increase efficiency and identify opportunities for service optimization. Service consumers use metrics to verify compliance with the requirements as specified during the service design stage and documented by the SLA. Service Monitoring provides a real-time view about the level of utilization, performance and status of the service as well as information about developing trends. The function of Service Reporting is to provide information about service performance and to enable the evaluation of the overall effectiveness of the service. If required, this information should be communicated to the service provider to initiate corrective measures. ITIL Continual Service Improvement processes adapted to cloud computing are listed in Table 5 below.

Table 5. ITIL Continual Service Improvement processes adapted to cloud computing

\begin{tabular}{|l|l|}
\hline \multicolumn{1}{|c|}{ ITIL Process } & \multicolumn{1}{|c|}{ Cloud consumer perspective } \\
\hline Service & $\begin{array}{l}\text { Develop suitable metrics that enable } \\
\text { proactive problem resolution }\end{array}$ \\
\hline $\begin{array}{l}\text { Service } \\
\text { Reporting }\end{array}$ & $\begin{array}{l}\text { Provide a mechanism to ensure that } \\
\text { service functionality is consistent with } \\
\text { the SLA }\end{array}$ \\
\hline
\end{tabular}

\section{CONCLUSION}

Cloud computing is changing the way that organizations utilize IT resources and impacts on the role of enterprise architecture, putting the emphasis on IT service management. ITIL is a widely used methodology for the implementation of IT Service Management that enables planning, design, selection, operation and continuous improvement of IT services. Applying the principles of ITIL provides organisations with methodology for managing IT services, but ITIL is primarily focused on on-premise solutions where resources are shared within a single organization. In this paper we have described our initial proposal for adapting the ITIL framework for the management of the lifecycle of cloud-based services. Taking the consumer perspective, we have redefined ITIL processes for the various lifecycle phases to reflect the needs of cloud service consumers. We have proposed that both cloud and on-premise IT services can be mapped to ITIL service lifecycle stages and that ITIL can be adapted to incorporate cloud services. The result of ITIL adaptation for cloud environments involves a revision of ITIL processes and the application of ITIL principles to implementation and management of cloud services. Our future efforts will focus on a more detail definition of the service interfaces between cloud consumers and cloud providers and on developing comprehensive specifications for processes for the various lifecycle phases.

\section{REFERENCES}

[1] C. Low, Y. Chen, and M. Wu, "Understanding the determinants of cloud computing adoption," Ind. Manag. Data Syst., vol. 111, no. 7, pp. 1006-1023, Aug. 2011.

[2] G. Feuerlicht, S. Schneider, and L. Tranter, "Towards Enterprise Architecture for Cloud Computing Environments," presented at the 11th Workshop on eBusiness, Orlando, FL 2012, 2012.

[3] S. Sutherland, "Convergence of interoperability of cloud computing, service oriented architecture and enterprise architecture," 2013.

[4] N. Khanghahi, R. Nasiri, and M. Razavi, "A New Approach Towards Integrated Cloud Computing Architecture," 2013. [Online]. Available: sdiwc.net/digital-library/web...pdf/00000878.pdf. [Accessed: 28-May-2014].

[5] R. Goel and V. Rishiwal, "Cloud Computing and Service Oriented Architecture," Int. J. Recent Technol. Eng. IJRTE, vol. April 2012, no. 1, pp. 137139, 2012.

[6] L. Aureli, A. Pierfranceschi, and H. Wache, "Enterprise Architectures for Cloud Computing," in 2013 IEEE Sixth International Conference on Cloud Computing, Los Alamitos, CA, USA, 2012, vol. 0, pp. 979-980.

[7] H. Wang, W. He, and F.-K. Wang, "Enterprise cloud service architectures," Inf. Technol. Manag., vol. 13, no. 4, pp. 445-454, Dec. 2012.

[8] D. Ebneter, S. G. Grivas, T. U. Kumar, and H. Wache, "Enterprise Architecture Frameworks for Enabling Cloud Computing," in 2010 IEEE 3rd International Conference on Cloud Computing (CLOUD), 2010, pp. 542-543.

[9] R. D. Zota and A. Fratila, "Toward the selection of an enterprise architecture model for a cloud environment," in Roedunet International Conference (RoEduNet), 2013 11th, 2013, pp. 1-6.

[10] Office of Government Commerce, ITIL [IT service management practices; ITIL v3 core publications]. London: TSO, 2007.

[11] P. S. Nelson Gama, "Integrating Enterprise Architecture and IT Service Management," 2012. 
[12] J. Vorisek, J. Jandos, and J. Feuerlicht, "SPSPR Model - Framework for ICT Services Management," J. Syst. Integr., vol. 2, no. 2, pp. 3-10, Apr. 2011.

[13] R. Radhakrishnan, "Enterprise Architecture \& IT Service Management.” The Open Group, 2008.

[14] M. Jansen, "Will Cloud Computing Change Standards in IT-Service Management?," Int. J. Comput. Commun., vol. 1, no. 6, p. 8, 2012.

[15] NIST Cloud Computing Standards Roadmap Working Group, M. Hogan, F. Liu, A. Sokol, J. Tong, "NIST Cloud Computing Standards Road map," National Institute of Standards and Technology, July 2011.

[16] C. Loebbecke, B. Thomas, and T. Ullrich, "Assessing Cloud Readiness: Introducing the Magic Matrices Method Used by Continental AG," in $2011 \mathrm{M}$. Nüttgens et al. (Eds.): Governance and Sustainability in IS, IFIP AICT 366, pp. 270-281, 2011.

[17] A. Rahimli, "Factors Influencing Organization Adoption Decision On Cloud Computing," in 2011 Int. J. Cloud Comput. Serv. Sci. IJ-CLOSER 2. doi:10.11591/closer.v2i2. 2111.

[18] M.D. De Assuncao, A. di Costanzo, R. Buyya, "Evaluating the Cost-benefit of Using Cloud Computing to Extend the Capacity of Clusters," in 2009 Proceedings of the 18th ACM International Symposium on High Performance Distributed Computing, HPDC '09. ACM, New York, NY, USA, pp. 141-150. doi:10.1145/1551609.1551635, 2009.

[19] Feuerlicht G. Enterprise SOA - What are the real benefits and challenges?, Proceedings of the 14th International Conference Systems Integration 2006, June 11-13, 2006, Prague, Czech Republic, ISBN 80-245-1050-2, pages 36-43.

[20] M. Kornevs, V. Minkevica, M. Holm, "Cloud Computing Evaluation Based on Financial Metrics," in Inf. Technol. Manag. Sci. 15, 87-92. 2012 